reduction in the numbers of care home staff accessing education at the hospice. Analysis of the contributing factors indicates that theoretical and clinical skills education is something the care home staff desire, however this needs to be easily accessible for them, on site and be delivered in a variety of ways which are meaningful for them in practice.

A three-month evaluation has already highlighted a 20\% increase in the number of residents with advance care plans, and homes now managing their own syringe driver set up, rather than using community nursing services.

\section{P-158 INTEGRATING A PALLIATIVE CARE APPROACH INTO THE NORMAL CARE PROVIDED IN CARE HOMES WITH NURSING}

David Smith, Sarah Brown. St. Luke's Hospice, Harrow, UK

\subsection{6/bmjspcare-2016-001245.181}

The need to provide high quality care for all people at the endof-life was identified in the End of Life Care strategy (Department of Health, 2008). Twenty one per cent of all deaths occur in care homes in England, highlighting the need for good end-oflife care for those who live within them (Public Health England, 2014).

In order to address this a hospice in North West London funded a facilitator role to empower staff in local care homes with nursing to provide high quality generic palliative care to those residents who may benefit from it. The aims of the post are to work with the homes to adopt a framework that helps staff to ensure that patients in the last year of life are identified, assessed and have an advance care plan put in place in accordance with their wishes. Further objectives are for nursing home staff to feel more confident to diagnose dying and manage the symptoms of residents who suffer advanced incurable illness.

To achieve the aims of the initiative the nursing home facilitator regularly visits the homes and discusses with staff all residents in their care, identifying any changes in their condition. To facilitate identification of appropriate patients a Prognostic Indicator Tool is used. Once identified patients are placed on a Supportive Register, which prompts nursing home staff to undertake advance care planning discussions and take appropriate actions.

A total of 161 staff have attended short training sessions delivered in the homes and End of Life Care Champion Training Sessions at the hospice. Whilst formal evaluation of the project is planned for September 2016, early indications are of an increased number of residents dying in those care homes who are working closely with the nursing home facilitator.

\begin{tabular}{lccc}
\hline & $\begin{array}{l}\text { Pre CHN facilitator post } \\
\text { September 2014 - March } \\
\text { 2015 }\end{array}$ & $\begin{array}{l}\text { Post CHN facilitator post } \\
\text { September 2015 - March } \\
\text { 2016 }\end{array}$ & Difference \\
\hline $\begin{array}{l}\text { CH with } \\
\text { Nursing A }\end{array}$ & 2 & 14 & +12 \\
$\begin{array}{l}\text { CH with } \\
\text { Nursing B }\end{array}$ & 8 & 14 & +6 \\
$\begin{array}{l}\text { CH with } \\
\text { Nursing C }\end{array}$ & 3 & 6 & +3 \\
\hline
\end{tabular}

\section{P-159 REFLECTIONS ON DELIVERING A PALLIATIVE CARE INTERVENTION IN ENGLISH CARE HOMES}

${ }^{1}$ Eleanor Sowerby, ${ }^{1}$ Danni Collingridge Moore, ${ }^{2}$ Lieve Van den Block, ${ }^{1}$ Katherine Froggatt, 'Sheila Payne. 'International Observatory on End of Life Care, Lancaster University, UK; 2End of Life Care Research Group, Vrije Universiteit Brussel and Ghent University, Brussels, Belgium

\subsection{6/bmjspcare-2016-001245.182}

Background Little is known about the process of implementing new palliative care interventions within care homes. The European Commission-funded PACE research project is a cluster randomised controlled trial of the 'PACE Steps to Success' intervention.

Aims To reflect on the experience of delivering facilitation for implementation of a palliative care intervention in English care homes.

Method Facilitation was delivered to six care homes on a monthly basis over a year by a clinically experienced trainer to staff. The PACE Steps to Success intervention uses a train-thetrainer approach by identifying key staff as PACE coordinators from within each care home. Implementation focused on: preferences for care, assessment, coordination of care, management of symptoms, and care in the last days of life and after death. Data recorded by the facilitator in a reflective diary was explored on the experiences of the site visits, recruitment to the training, implementation, delivery and uptake of the intervention. Factors that supported and hindered the use of the intervention were identified.

Results Supportive factors: Identified PACE coordinators in the care homes helped promote staff engagement and interest in palliative care. The Nursing and Midwifery Council revalidation system motivated staff attendance at training sessions. Certificates were issued following the completion of all taught sessions. Social media was introduced to create a forum for communication and help promote sustainable support and peer networks.

Barriers: Barriers to the implementation were changes in the employment of care home managers, coupled with poor communication impacted on recruitment of staff to training sessions and use of new tools.

Conclusion Delivering new interventions in the care home sector is influenced by limited resources and competing pressures on staff. It's possible to implement a palliative care intervention in care homes, when managers are supportive and staff are enabled to work in partnership with the trainer.

\section{P-160 THE DEVON CARE HOME KITEMARK - HOW MIGHT PEER-REVIEW AND PEER-LEARNING IMPROVE END OF LIFE CARE IN CARE HOMES?}

${ }^{1}$ George Coxon, ${ }^{2}$ Becky Baines. 'Classic Care Homes (Devon), Exeter, UK; ${ }^{2}$ Hospiscare, Devon

10.1136/bmjspcare-2016-001245.183

The Devon Care Home Kitemark is in its fifth year and has established a strong provider-led coalition, with over 60 member residential care homes. The homes are committed to sharing learning, promoting collaboration and using evidence to enhance best practice. 2016 has seen the movement identify 6 priority topics, including end-of-life care.

The Kitemark approach so far has been to engage and empower residential care homes. The team have used an 'appreciative inquiry' model to create a group of 'critical friends' who 
share knowledge, tools and techniques for improving care for residents.

Using the impetus of "Dying Matters" week in May 2016, the Devon Care Home Kitemark group have now established a plan for a peer-review pilot of End of Life Care in their homes.

The initial pilot visits will be undertaken in Summer 2016, with a view to developing a process to be used across all 60 sites.

Methods included will be:

- Site visits undertaken by peers, with the support of the local specialist palliative care team where appropriate.

- Completion of peer review feedback sheets to clarify strengths and challenges for each home.

- The process will be developed and refined over time, according to feedback from staff, residents and managers.

Rather than using existing models of teaching and training in care homes (eg. Six Steps, GSF for Care Homes), which have to date been led by "experts", this work has uniquely been driven by care homes themselves. The aim is that homes will be able to make quality improvements in a meaningful, sustainable way.

By looking carefully at generic challenges for the Kitemark Homes in the local area, a further key aim will be to identify how to improve End of Life care across boundaries for our care home residents.

\section{P-161 ABSTRACT WITHDRAWN}

\section{P-162 CHAMPIONING SPECIALIST CARE AT HOME IN EVERYDAY DYING}

Nicola Woodyatt, Sridevi Singh. Macmillan Cancer Support, London, UK

\subsection{6/bmjspcare-2016-001245.184}

The cancer story is changing, by 2020, almost one in two people will get cancer and $47 \%$ of those who died that year will have had cancer. We are reminded that choice at the end of life is so important and Macmillan wants everyone to have more choice.

This session looks at the Macmillan Specialist care at Home partnership approach to providing palliative care to people in the community. It's based on the successful model developed in Midhurst where people experienced less frequent $\mathrm{A}$ and $\mathrm{E}$ attendances, decreased hospital stays and a majority of people died in their preferred place. Macmillan have since identified and supported six innovation centres that have adopted this model.

Each centre has adopted the model of person-centred care, which emphasises principles such as having a consultant led multidisciplinary team - doctors, nurses, clinical nurse specialist, occupational therapist, physiotherapists and counsellors; flexible teamwork between specialists, generalists and trained volunteers in the community. This has enabled timely referral, home-based clinical interventions and close, flexible collaboration between primary care and other community-based services. Each centre is working in partnership with many different partners such as commissioners of end of life care, community/hospital providers and hospices.

The philosophy that makes the Macmillan Specialist Care at Home approach so successful is to ensure that the person and their families feel well supported and they receive personalised, coordinated care and this session will showcase some of the findings of this project.

\section{SO FAR}

${ }^{1}$ Karen Taylor, ${ }^{1,2}$ Simone Ali, ${ }^{2}$ Mags Bunting. ${ }^{1}$ Martlets Hospice, Hove, UK; ${ }^{2}$ Sussex Community NHS Foundation Trust

10.1136/bmjspcare-2016-001245.185

Introduction In April 2013 the Palliative Care Partnership, a collaboration between a NHS Community Palliative Care Team and a charitable Hospice at Home service was commissioned to provide community palliative/end of life care for patients in the local area.

Aims of service Improve outcomes for all patients locally with palliative/end of life care needs, regardless of diagnosis

Improve patient and carer experience

Maximise use of existing resources by reducing duplication and optimising efficiency: "right care, right time, right place".

Methods More joined-up approach to care/support achieved by:

- Single point of access $24 / 7$ via telephone hub, manned by NHS and hospice staff

- Joint triage system

- 7 day week visiting service

- Shared electronic patient record system

- Joint multidisciplinary meetings

- Joint governance framework

- Collaboration with other services.

Results Successes:

- Key Performance Indicators (KPIs) met/exceeded

- Reduction in inappropriate hospital admissions (>10/month, a saving of at least $£ 200,000$ /annum to local health economy)

- Dying in Preferred Place of Care increased to 89\%

- Telephone hub activity increased by over $50 \%$ out of hours

- $64 \%$ increase in first year in number of referrals with highly complex needs

- Carer feedback shows $83 \%$ received help as often as they needed

- Excellent feedback from local services

- Rating of "Outstanding" for responsiveness in Trust's latest CQC inspection.

Challenges:

- Demand on telephone hub soon exceeded capacity. Given the cost effectiveness of the service and impact on outcomes, additional resource was awarded by the commissioners

- Merging two organisations with different cultures, funding arrangements and systems. The common goal of high quality patient-centred care helped to overcome these challenges

- Data collection has been time consuming. We are currently refining our processes.

Conclusions Partnership working can significantly benefit patients and carers and be cost effective. KPIs need to be reviewed regularly to drive further improvement. Data collection and audit are key for service development.

\section{P-164 VOLUNTEERS AT LIFE'S END - VALE - IN THE COMMUNITY}

Andrew Lowden, Sheila Markham. LOROS, Leicester, UK

10.1136/bmjspcare-2016-001245.186 